\title{
THE BIOLOGY OF CERATOPHYLLUS FASCIATUS BOSC., THE COMMON RAT-FLEA OF GREAT BRITAIN 1 .
}

\author{
By C. STRICKLAND, M.A., B.C. \\ Assistant to the Quick Professor of Biology in the \\ University of Oambridge.
}

\section{(From the Quick Laboratory, Cambridge.)}

Is view of its possible relation to the epidemiology of plague, a knowledge of the biology of the common rat-flea of England, Ceratophyllus fasciatus Bosc., is much to be desired, and therefore, at the request of Professor Nuttall, the present investigation was undertaken. The observations recorded below are mainly the result of experimental work with fleas conducted in the Quick Laboratory, Cambridge; but before proceeding to a description of the experiments it is considered advisable to give a short summary of the life-cycle of the rat-flea

\section{Life-cycle of the rat-flea.}

The life-cycle of Ceratophyllus fasciatus is made up of four successive stages, viz., the egg, larva, pupa, and, finally, the adult insect, or imago.

The egg is an oval, translucent body, pearly-white in appearance, which adheres slightly to the material on which it is laid. When dead it loses its lustre and becomes tawny-yellow in colour. Its length is

1 This paper was sent in February, 1913, for publication in The Annual Report of the Medical Officer of the Local Gov't Board. It is reprinted, by permission of $\mathrm{H}$. M. Stationery Office, from the 42nd Annual Report to the Local Gov't Board, 1912-13 (Supplement containing the Report of the Medical Officer. To be purchased from Wyman \& Sons, Ltd, Fetter Lane, London, E.C., or through any publisher. Ed.).

Journ. of Hyg. xIV 


\section{Strickland}

one or two rats were kept in wire cages resting on this rubbish and contained in the large glass box or jar. Under these conditions the fleas multiplied rapidly, and usually plenty of larvae could be obtained by searching the rubbish. Eggs were easily obtained by placing gravid females in a box containing a piece of black cloth. After the lapse of a few hours, numerous eggs could usually be found adhering to the cloth, on which they were easily seen.

\section{Preliminary Experiment on the Individual Range in the Rate of Development.}

In order to determine whether the rat-flea shows any considerable inherent variation in the rate of its development, a batch of 73 eggs, all laid on the same day, were kept together under the same conditions. Of these eggs 1 hatched in 10 days; 4 in 11 days; 25 in 12 days; 31 in 13 days; 10 in 14 days; 1 in 15 days; and 1 in 16 days. From this range of variation it is evident, therefore, that no just conclusions can be drawn from a few isolated observations, and this point has been kept in view throughout the following experiments.

\section{Description of Experiments.}

I. Experiments with the ovum :

(a) The effect of various conditions of temperature and humidity.

(b) The presence or absence of delayed hatching.

(c) The influence of temperature and humidity on the percentage of eggs that hatched.

II. Experiments with the larva:

(a) The effect of various conditions upon the duration of the larval stage.

(b) The most favourable food.

(c) Light reactions.

III. Experiments with the pupa:

(a) The influence of external conditions upon the duration of the pupal stage.

IV. Experiments with the imago :

(a) Longevity, when fed.

(b) Longevity, when unfed. 
(c) Hosts on which it may feed.

(d) Preference for hosts.

(e) Copulation and oviposition.

(f) Reaction to light and air.

(g) Jumping powers.

I. Experiments with the Ovum.

(a) The effect of various conditions of temperature and humidity. The effect of these conditions on the incubation period of the egg is shown in the accompanying Table (I):

TABLE I. Incubation period of egg.

\begin{tabular}{|c|c|c|c|c|c|c|c|c|c|}
\hline \multirow[b]{2}{*}{ Exp } & \multirow{2}{*}{$\begin{array}{l}\text { No. } \\
\text { of } \\
\text { eggs }\end{array}$} & \multirow{2}{*}{\multicolumn{2}{|c|}{$\begin{array}{c}\text { Where laid } \\
\text { and kept }\end{array}$}} & \multirow{2}{*}{$\begin{array}{l}\text { Date when } \\
\text { laid }\end{array}$} & \multirow{2}{*}{$\begin{array}{c}\text { Date of } \\
\text { hatching }\end{array}$} & \multirow{2}{*}{$\begin{array}{c}\text { Average } \\
\text { temp.; } \\
\text { Fahr. }\end{array}$} & \multirow{2}{*}{$\begin{array}{l}\text { Average } \\
\text { humidity } \\
\text { (wet and } \\
\text { dry bulb) } \\
\text { per cent. }\end{array}$} & \multicolumn{2}{|c|}{$\begin{array}{c}\text { Incubstion } \\
\text { period in days }\end{array}$} \\
\hline & & & & & & & & Range & Average \\
\hline 1 & 45 & \multicolumn{2}{|c|}{$\begin{array}{l}\text { Glass house in } \\
\text { laboratory }\end{array}$} & 3-7. v. 11 & $9-13$. จ. 11 & $7^{\circ}$ & $35-40$ & $5-7$ & 6 \\
\hline 2 & 12 & ", & $"$ & 5-8.xII. 11 & 11-14. xIr. 11 & $70^{\circ}$ & 55 & - & 6 \\
\hline 3 & 10 & & ," & 30. xr. 10 & 6. xII. 10 & $70^{\circ}$ & 50 & - & 6 \\
\hline 4 & $\begin{array}{l}\text { about } \\
48\end{array}$ & \multicolumn{2}{|c|}{$\begin{array}{l}\text { Incubator un- } \\
\text { der bell-jar }\end{array}$} & - & - & $90^{\circ}$ & 100 & \multicolumn{2}{|c|}{ 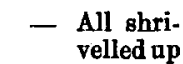 } \\
\hline 5 & 44 & \multicolumn{2}{|c|}{$\begin{array}{l}\text { Open vessel in } \\
\text { laboratory }\end{array}$} & 29.Iv-2.v.11 & $8-12$. v. 12 & $59 \cdot 5^{\circ}$ & 66 & $8-10$ & 9 \\
\hline 6 & 6 & " & $"$ & $\begin{array}{c}\text { Summer, } \\
1909\end{array}$ & - & - & - & 5-9 & 7 \\
\hline 7 & 10 & ", & , & , & - & $63^{\circ}$ & 70 & $5-6$ & $5 \frac{1}{2}$ \\
\hline 8 & 2 & , & ", & ", & - & - & - & - & 7 \\
\hline 9 & 74 & & ," & 30. xI. 11 & $10-16$. xIr. 11 & $59^{\circ}$ & 82 & - & 13 \\
\hline & 62 & \multicolumn{2}{|c|}{ Engine room } & 13. จ. 11 & 19-21. v. 11 & $58^{\circ}$ & $60-65$ & $6-8$ & 7 \\
\hline & 51 & \multirow{2}{*}{\multicolumn{2}{|c|}{$c$}} & 11. จ. 11 & 18-21. จ. 11 & $57^{\circ}$ & 72 & - & 8 \\
\hline & 7 & & & $1-2 . x 11.11$ & $13-14 . x I x .11$ & $55^{\circ}$ & 75 & - & 12 \\
\hline
\end{tabular}

Hatching occurred most rapidly (in $5 \frac{1}{2}$ to 6 days) at $63^{\circ}$ to $73^{\circ} \mathrm{F}$., the atmospheric moisture varying between 35 and 70 per cent. Hatching occurred on the 7 th, 8th, and 9 th days at $57^{\circ}$ to $59.5^{\circ} \mathrm{F}$., the atmospheric humidity ranging between 60 and 72 per cent. Hatching was delayed to the 12 th and 13 th day at $55-59^{\circ} \mathrm{F}$., the humidity ranging between 75 and 82 per cent, and hatching did not occur when the eggs were maintained at $90^{\circ} \mathrm{F}$. in a saturated atmosphere.

(b) The presence or absence of delayed hatching. In the case of the body-louse, Pediculus vestimenti, Warburton (1910) has observed that under certain conditions the hatching of the egg may be considerably delayed. Accordingly, the possibility of such a property being present in the eggs of theas was carefully investigated. In many cases, eggs 
were observed for periods up to two months after they had been laid, but whenever the incubation period was unduly prolonged the eggs were found to be dead. Therefore, the presence of delayed hatching has not been observed in our experiments with Ceratophyllus fasciatus.

(c) The influence of temperature $\left(57-73^{\circ} \mathrm{F}\right.$.) and humidity (35-72 per cent.) on the percentage of eggs that hatched appears to be quite insignificant, as shown in the following experiments made to determine this point:

$\begin{array}{ccccc}\begin{array}{c}\text { Number of } \\ \text { experiment }\end{array} & \begin{array}{c}\text { Number of } \\ \text { eggs laid }\end{array} & \begin{array}{c}\text { Temperature: } \\ \text { Degrees } \\ \text { Fahrenheit }\end{array} & \begin{array}{c}\text { Humidity } \\ \text { percentage }\end{array} & \begin{array}{c}\text { Percentage } \\ \text { of eggs } \\ \text { that hatched }\end{array} \\ 1 & 55 & 59 \cdot 5 & 66 & 80 \\ 2 & \mathbf{8 0} & 58 & 60-65 & 75 \\ 3 & \mathbf{7 3} & 57 & 72 & 70 \\ 4 & 64 & \mathbf{7 3} & \mathbf{3 5 - 4 0} \therefore \ldots & \mathbf{7 0}\end{array}$

It will be noticed that the temperature and humidity conditions during experiments 3 and 4 were very different, and yet the percentage of eggs which hatched out was exactly the same.

In conclusion, it may be said that the egg hatehes out after a relatively short incubation period (5-14 days), the duration of which depends mainly on the degree of humidity. The incubation period is never abnormally prolonged, as in the case of lice, and varging conditions of temperature and humidity have practically no effect on the percentage of eggs which ultimately hatch.

\section{Experiments with the Larva.}

(a) The effect of various conditions. Unfortunately, out of the larvae which were kept under observation, very few lived throughout the whole stage and pupated, and in consequence our results are somewhat imperfect.

Usually, the larvae were placed in Petri dishes, each of which contained some particular food-stuff. They were then kept in the dark under varying conditions of temperature and humidity. The results are given in the accompanying Table (II).

From these results it will be seen that a low temperature combined with a high degree of humidity is more favourable to the longevity of the larvae than the opposite condition. (Compare Experiments 3, 5, 8, and 9 with 4 and 6.) Although none of the larvae which were fed on powdered rat-faeces managed to reach the pupal stage, we do not consider that this lack of success was due to the food-a point of view 


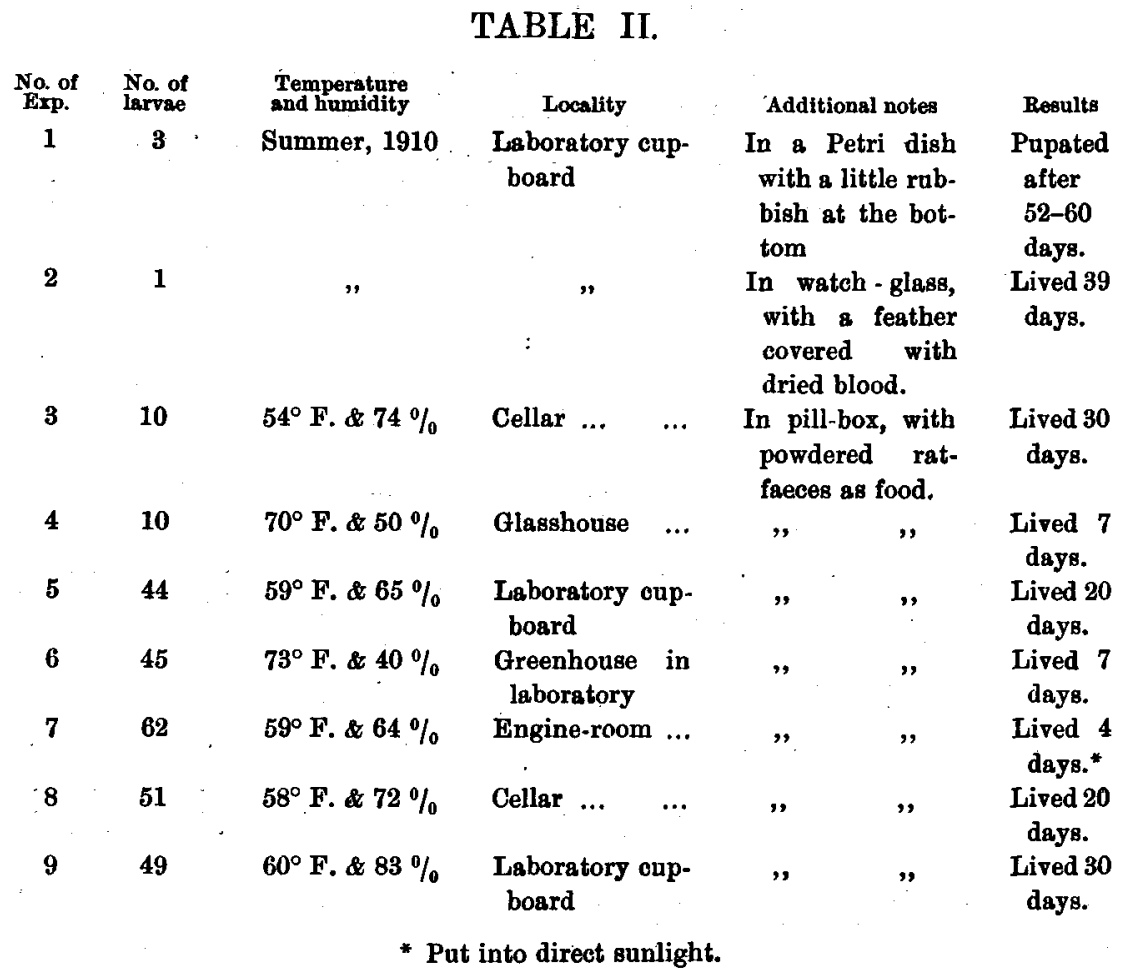

which is supported by the experiment described under the next heading (b). The reason that so few of the larvae ever came to maturity in these experiments was that they were usually placed in a glass dish containing only a small quantity of dry food, and nothing in the nature of a substratum of rubbish in which they might bury themselves. In the only experiment (1) in which a substratum was provided the larvae successfully reached the pupal stage. It may be added that when breeding fleas in boxes the larvae are always more abundant in those parts of the rubbish that are slightly damp. The conditions which seen to be suitable for the larva resemble those that are most favourable to the imago, for the adult unfed flea will live a very much longer time amongst hygroscopic rubbish than in its absence.

To summarise, the most favourable condition for the larva is a low temperature combined with a high degree of humidity; further, the presence of rubbish, in which the larva may bury itself, is essential to its successful development. 
(b) The most favourable food. When larvae are placed in a bottle containing either wood-wool soiled by excrement, or with feathers or filter-paper covered with dried blood, they will thrive readily and pupate. An experiment was made to see whether dried blood or rat-faeces is most favoured. About 50 newly-hatched larvae were placed in a pillbox containing, on one side, filter-paper covered with dried blood, and on the other side, powdered rat-faeces. The larvae were found to wander from one to the other indiscriminately. The larva possesses the curious habit of always devouring its moulted skins.

(c) Light reactions. The larva is very sensitive to light, especially in its younger stages, and exposure to direct sunlight is rapidly fatal. Newly-hatched larvae invariably hide themselves away from the light, creeping underneath any dark objects at the bottom of the dish. Nevertheless, full grown larvae, if kept in the light, will manage to pupate.

To summarise the foregoing observations on this stage of the lifehistory, it may be stated that the larva is very susceptible to external conditions, and is not very "hardy." It readily feeds on flea-excrement, dried blood, and powdered rat-faeces. It is photophobic, especially in its younger stages.

\section{Experiments with the Pupa.}

The influence of external conditions on the duration of the pupal stage. The following experiments have been performed in order to determine the duration of the pupal stage under various external conditions:

1. A pupa, formed during July, 1910, was kept in a dark cupboard in the laboratory; the imago emerged after 17 days.

2. A batch of 30 to 40 "naked" pupae (i.e. without cocoons) were under observation for four to five weeks before the imagines emerged. The time of the experiment was April and May, 1910.

3. In October, 1911, a batch of freshly-formed cocoons was placed in a small dish that was kept near a white rat in a deep glass jar in the laboratory. Two months later one small and feeble flea was found on the rat, but no more of them emerged until February-a period of four months. Eight of the cocoons were then dissected, and seven of them were found to contain the imago, which was fully formed, but in a resting state. The remainder of the batch were then placed in the warm glass house of the laboratory $\left(70^{\circ} \mathrm{F}\right.$.) for one night near a white rat; the next day all the cocoons were empty, and the fleas were found on the rat. 
From these experiments it is apparent that the temperature greatly influences the duration of the pupal stage. Moreover, when metamorphosis is complete a low temperature will cause the imago to remain within the cocoon.

\section{Experiments with the Imago.}

(a) Longevity, when fed. One experiment was performed in order to determine the longevity of fleas when regularly fed on blood.

A number of fleas were fed through ganze on a rat at various intervals for two months. During this period the insects remained alive and healthy, frequently copulating and laying eggs. The experiment was then discontinued. It is evident, therefore, that, even when sexually mature and ovipositing, the flea does not possess a short life.

(b) Longevity, when unfed. The experiments performed in order to determine the longevity of fleas when unfed fall into two groups, according as to whether or not the insects were kept on a substratum of more or less hygroscopic rubbish. In every case many hundreds of fleas were used.

The result of keeping unfed fleas in the presence of hygroscopic rubbish is shown in the following Table (III):

\section{TABLE III.}

\begin{tabular}{|c|c|c|c|}
\hline $\begin{array}{l}\text { No. of } \\
\text { Exp. }\end{array}$ & $\begin{array}{c}\text { Locality } \\
\text { temp. and humid. }\end{array}$ & $\begin{array}{l}\text { Quantity of } \\
\text { substratum }\end{array}$ & Result \\
\hline 1 & Cellar passage & Small amount & $\begin{array}{l}\text { Many alive after } 2 \text { weeks; only one or two } \\
\text { after } 9 \text { weeks. }\end{array}$ \\
\hline 2 & $\begin{array}{l}\text { Laboratory } \\
\left(60^{\circ} \mathrm{F} . \& 70^{\circ} \%\right)\end{array}$ & Large amount & $\begin{array}{l}\text { Large numbers alive after } 17 \text { weeks (December, } \\
\text { 1910), and also after } 7 \text { months (March, 1911): } \\
\text { but during the hot summer of } 1911 \text { very } \\
\text { many died. On the return of the winter } \\
\text { months many were still alive and active up } \\
\text { to February, 1912, after being without food } \\
\text { for } 17 \text { months. They were then acciden- } \\
\text { tally thrown away. }\end{array}$ \\
\hline $\mathbf{3}$ & $\begin{array}{l}\text { Greenhouse } \\
\left(70^{\circ} \mathrm{F} \cdot \& 45 \%\right)\end{array}$ & Large amount & All died within 4 months. \\
\hline 4 & Cellar & $\begin{array}{l}\text { Small amount, } \\
\text { but more than } \\
\text { in Exp. } 1\end{array}$ & $\begin{array}{l}\text { All died within } 4 \text { months; but many were } \\
\text { alive after } 3 \text { months. }\end{array}$ \\
\hline
\end{tabular}

To make certain that the continued presence of the fleas was due to the persistence of the original insects and not to a constant accession of freshly-hatched ones, the following experiments were performed: 
(I) Some of the rubbish in which the fleas were living was put into a Petri dish and all imagines carefully removed. The dish was then kept under close observation for 4 months, but no fleas ever appeared in it.

(2) Some of the imagines were isolated but did not lay any eggs, nor were larvae ever noticed in the flea rubbish. It is evident, therefore, that no active breeding was taking place, and the presence of fleas must be attributed to the persistence of the original individuals.

On the other hand, the result of keeping unfed fleas in the absence of any substratum of rubbish is well shown in the following Table (IV):

\section{TABLE IV.}

\begin{tabular}{|c|c|c|c|c|c|}
\hline $\begin{array}{l}\text { No. of } \\
\text { Exp. }\end{array}$ & Locality & $\begin{array}{c}\text { Tempers- } \\
\text { ture }\end{array}$ & Humidity & Substratum & Result \\
\hline 1 & Cellar passage & - & - & Nil & Died after 31-38 days. \\
\hline 2 & Cellar $\quad \ldots$ & - & 一 & Nil & Died after 25-32 days. \\
\hline $\mathbf{3}$ & Laboratory & - & - & $\begin{array}{l}\text { Moist silver } \\
\text { sand }\end{array}$ & Died after 32-43 days. \\
\hline 4 & $\begin{array}{l}\text { Greenhouse in } \\
\text { Laboratory }\end{array}$ & $70^{\circ} \mathrm{F}$ & $40 \%$ & Nil & Died after 25-31 days. \\
\hline 5 & Incubator & $77^{\circ} \mathrm{F}$. & 一 & Nil & Died after $1-3$ days. \\
\hline 6 & Incubator & $77^{\circ} \mathrm{F}$ & - & $\begin{array}{l}\text { Moist silver } \\
\text { sand }\end{array}$ & Died after 1-2 days. \\
\hline 7 & $\begin{array}{c}\text { 'Temperate Pit,' } \\
\text { Botanic Gardens }\end{array}$ & $60^{\circ} \mathrm{F}$ & $60 \%$ & $\mathrm{Nil}$ & Died after 27-38 days. \\
\hline 8 & $\begin{array}{l}\text { 'Stove Pit,' Bo- } \\
\text { tanio Gardeng }\end{array}$ & $65^{\circ} \mathrm{F}$. & $57 \%$ & Nil & Died after 27-38 days. \\
\hline 9 & Cellar ... $\quad .$. & $55^{\circ} \mathrm{F}$. & $80 \%$ & Nil & Died after 17-24 days. \\
\hline
\end{tabular}

From the results of these two series of experiments it is evident that if the adult flea does not obtain food in the form of blood, its length of life depends mainly on the nature of its surroundings. In the presence of rubbish, in which it can bury itself, the flea may live for many months, whereas in the absence of any such substratum it very rarely lived a month. In the former case the length of life is influenced to some degree by the temperature and humidity, for in Experiment 3 (Table III), carried out at $70^{\circ} \mathrm{F}$. and 45 per cent. humidity, the fleas did not live for more than four months, whilst in Experiment 2, with an average temperature of $60^{\circ} \mathrm{F}$. and 70 per cent. humidity, they lived for at least 17 months. A low temperature combined with a high degree of humidity appears, therefore, to be most favourable to the prolongation of the life of this insect. In this connection, it may be pointed out that in Experiment 2 (Table III), it was very noticeable how large a number 
of fleas died off during the summer, whilst in the winter months no diminution in numbers could be detected.

When the fleas are kept without any rubbish, the conditions of temperature and humidity seem to have little effect on the length of life (Table IV).

A few experiments have been performed with the object of explaining why tleas will live in a mass of rubbish for such a long time without any food. In order to determine whether the insect actually sucks up moisture from surrounding objects, several fleas that had been without food for several months were placed on filter-paper that had been moistened with a solution of neutral-red. The fleas were afterwards dissected, but no trace of colouring matter was found in their intestines.

It has also been observed that when fleas in bell-jars are supplied with an extract of flea-rubbish on filter-paper, they do not live any longer than those which are not thus supplied. It appears, therefore, that fleas do not suck up moisture from surrounding objects.

We suggest that the flea probably survives by creeping into husks of grain, or under pieces of straw, in which situations it is not only cool, but also supplied with a certain degree of moisture favourable to its persistence.

(c) Hosts on which it may feed. In addition to its normal host, the rat, C. fasciatus will feed on a variety of animals. As, however, Tiraboschi (1904), and Strickland and Merriman (1912) have previously given lists of animals on which this flea has been found, we shall proceed directly to a description of the experiments. In addition to determining whether the flea would feed on any particular host, the insects have been kept under observation to see if they could breed on such animals.

\section{Experiments with Man.}

\begin{tabular}{|c|c|c|}
\hline \multirow[t]{4}{*}{ Experiment 1} & $27 / 11 / 11$ & One $C$. fasciatus taken from a wild rat. \\
\hline & $28 / 11 / 11$ & Refused to feed on two men (E. H. and G. M.). \\
\hline & $29 / 11 / 11$ & Fed on G.M. \\
\hline & $1 / 12 / 11$ & Fed on C. B. \\
\hline Experiment 2 & $1 / 12 / 11$ & Two C. fusciatus put on man (Е. H.); fed. \\
\hline Experiment 3 & $1 / 12 / 11$ & $\begin{array}{l}\text { Three } C \text {. fasciatus, starved for a fortnight, fed readily on } \\
\text { G. M. }\end{array}$ \\
\hline Experiment 4 & $6 / 12 / 11$ & Eight $C$. fasciatus, starved for many months, fed on C.S. \\
\hline Experiment 5 & $6 / 12 / 11$ & Five C. fasciatus, starved for many months, fed on C. S. \\
\hline
\end{tabular}


From the foregoing results it is evident that $C$. fasciatus will readily feed on man, and in this respect we confirm the work of Chick, Martin and Rowland (1911). On the other hand, fleas that had fed only on human blood could never be induced to lay eggs, and therefore it is probable that $C$. fasciatus would not be able to become established if it could only feed on man. Several fleas were fed for four successive days on C.S., but although the insects were kept under observation for some time, no eggs were laid.

On the other hand, a number of the same lot of fleas that were fed on a rat at the same time, laid eggs shortly after the meal.

\section{Experiments with a Rabbit.}

A rabbit was put into a flea-box containing a large number of hungry fleas and taken out after a few hours. The majority of the fleas were then found to be gorged with blood, evidently having fed on the rabbit. Several of the gorged females were then placed in a Petri dish, but no eggs were laid, although some of the same lot of females when fed on a rat at once laid eggs.

\section{Experiments with the Mouse.}

A large number of fleas were placed on a mouse. Although they readily became gorged on this host, none of the females laid any eggs. From these experiments it appears that, although the rat-flea will readily suck the blood of various animals, yet the rat is the only true natural host, as in no other case was the meal followed by oviposition.

(d) Preference for hosts. It is generally assumed that Ceratophyllus fasciatus prefers its normal host, the rat, to any other animal ; but the following experiments do not support this supposition, at least, as far as man is concerned.

A long glass tube, about 2 inches in diameter, was taken, and at the middle of its length was placed a batch of fleas contained in a small tube. One end of the glass tube was then applied to a rat and the other to the bare arm of a man. As the fleas escaped from the small tube they nearly always went towards the hare arm and fed on human blood. The experiment was then repeated with the positions of the two hosts reversed; but exactly similar results were obtained.

In the first case, eight fleas went towards the man and one to the rat, whilst in the second, five fleas went to the man and one to the rat. It 
is evident, therefore, under these conditions man is much more attractive to the flea than the rat?

(e) Copulation and Oviposition. A certain number of experiments and observations were made to determine the effect of various conditions on these two processes.

(1) Fleas just hatched were allowed to feed on a rat for successive days up to a week later, but the insects were never observed in copula.

(2) Fleas found in copula were placed in a Petri dish in the laboratory, and within 24 hours several eggs were laid.

(3) Fleas which were kept without food for long periods in order to test their longevity were never observed to copulate nor lay any eggs, although many of the insects were isolated and kept in a Petri dish.

(4) A batch of fleas which had been starved for a month and were not laying eggs were put on a rat for 24 hours and then taken off and placed in a Petri dish. The next day several eggs had been laid. The fleas were then removed to another Petri dish without having another feed, but no more eggs were laid.

(5) Fleas were fed through fine gauze on rats, and copulation immediately took place between several couples. We have often observed that, as soon as fleas are fed, the males wander about and copulate with the females, even while the latter are still sucking blood. The frequency of copulation seems to depend on the number of times the fleas are fed.

(6) A batch of fleas that had been starved for many months was placed on a rat for 24 hours, and within the next 24 hours many eggs were laid.

(7) During December, 1911, a batch of fleas was placed on a rat in a cold cellar, the average temperature of which was $50^{\circ} \mathrm{F}$. and its humidity 80 per cent. These fleas when put into a dish laid eggs, and in addition larvae were seen in the rat's nest on February 15th-about two months later.

(8) A batch of fleas were repeatedly fed through gauze on a rat for a period of two months, during which time they frequently copulated and laid eggs. The experiment was then discontinued.

On summarising the above-described experiments, it appears that fleas do not copulate until they are sexually mature, and that for some time after emerging from the pupa their reproductive organs are still

\footnotetext{
I It is possible that in these experiments the fleas were influeneed by a difference of temperature; as shown by Howlett (1910), in the case of mosquitoes.
} 
imperfectly developed. When mature, copulation is always followed by oviposition within a very short time. Copulation takes place soon after the fleas have fed on their true host_the rat-but not if they have fed on a facultative host, such as man. In the absence of food the fleas are never observed to either copulate or lay eggs.

The effect of the rat's blood on the female with regard to egg-laying seems to be rather stimulating than nutritive, as fleas that have been without food for many months will lay eggs immediately after they are fed. Similarly, the male requires the stimulus of a meal of rat's blood before it displays any copulatory activities.

Both of these processes will take place in a rat's nest during the winter months, and therefore the temperature does not appear to be a very important factor.

In conclusion, the sexual life of the flea certainly lasts for at least eight weeks.

$(f)$ Reaction to light and air. The fleas were always to be found hiding under dark objects and very seldom seen in the light, which is evidently much disliked by them. Moreover, they are very sensitive to air-currents, for when a number of fleas are blown upon they at once become very agitated.

(g) Jumping powers. The average flea is able to jump a distance of about 3 inches, when gorged, and about 4 inches when starved. It is also capable of walking up a vertical sheet of glass for about 8 inches, after which it falls back to the ground.

\section{Summary of Conclusions on the Life-history of the Flea.}

Our conclusions with regard to the above-described experiments have been given in detail at the end of each section, but we here append a short and condensed summary of the main features :

1. The duration of the various stages is very variable even under the same conditions.

2. Temperature and humidity are the two conditions which have most influence on the duration of the various stages. On an average, the egg hatches out in 5-14 days, an increase of humidity having a retarding, and a moderately high temperature a slight accelerating effect. The larva is soon killed by a high temperature $\left(70^{\circ} \mathrm{F}\right.$.) combined with a low degree of humidity ( 40 per cent.). However, under these conditions, the larvae will live longer if rubbish is present, for they are then able to bury themselves in it and thus obtain a certain amount of 
moisture. The pupal stage is much prolonged by cold, but this is partly due to the non-emergence of the imago even when it is fully formed.

The imago, at least when unfed, dies off much more rapidly in summer than in winter. Eggs are laid by the imago even at comparatively low temperatures $\left(50^{\circ} \mathrm{F}\right.$.).

3. The larva and imagines like to bury themselves in rubbish, and under these circumstances their duration of life is much prolonged, even when other external conditions are somewhat severe.

4. When copulating, the imago frequently lives at least two months, but it will not copulate unless it is fed on rat's blood. It feeds readily on man and many other animals, but will not copulate after feeding on these facultative hosts, even though at least one of them-man-seems to be more attractive to it than its normal host, the rat. Oviposition invariably takes place within 24 hours of copulation, even when the insect has only been fed once after being starved for a period of many weeks. The rat's blood, therefore, probably contains some substance that possesses a stimulating effect on the flea's sexual organs. When starved, the imago will live for a very long time-at least 17 monthsbut only in the presence of rubbish in which it can bury itself. In the absence of rubbish the flea will only live for about a month, even under the most favourable conditions of temperature and humidity.

5. From the foregoing observations it is clear that the presence of rubbish containing organic matter is essential for the development of the flea.

We are greatly indebted to Professor Nuttall for his kind help and advice in this work, and for many suggestions which were made use of in the experiments. Our thanks are also due to Dr E. Hindle for his careful revision of this paper.

\section{REFERENCES.}

Chick and Martin (1911). Journ. of Hygiene, xI. 122.

Howlett (1910). Parasitology, IIr. 479-484.

Indian Plague Commission (1906-1910). Journ. of Hygiene, vI. vII. vIII. and IX.

Martin and Rowland (1911). Reports to the Local Government Board on Public Health and Medical Subjects, N.S. No. 52.

Strickland and Merriman (1912). Report of the Medical Officer to the Local Government Board, 1911-1912, pp. 336-348.

Trraboschi (1904). Arch. de Parasitologie, viri. 161.

Warburton (1910). Reports to the Local Government Board on Public Health and Medical Subjects, N.S. No. 27. 